\title{
Magnetic signature of large exhumed mantle domains of the Southwest Indian Ridge - results from a deep-tow geophysical survey over 0 to 11 Ma old seafloor
}

\author{
A. Bronner ${ }^{1}$, D. Sauter ${ }^{1}$, M. Munschy ${ }^{1}$, J. Carlut ${ }^{2}$, R. Searle ${ }^{3}$, M. Cannat ${ }^{2}$, and G. Manatschal ${ }^{1}$ \\ ${ }^{1}$ Université de Strasbourg, Institut de Physique du Globe de Strasbourg (IPGS) UMR CNRS, Strasbourg, France \\ ${ }^{2}$ Sorbonne Paris Cité Université Paris Diderot, Institut de Physique du Globe de Paris (IPGP), UMR CNRS, Paris, France \\ ${ }^{3}$ Durham University, Department of Earth Sciences, Durham, UK
}

Correspondence to: A. Bronner (a.bronner@unistra.fr)

Received: 2 December 2013 - Published in Solid Earth Discuss.: 23 December 2013

Revised: 18 March 2014 - Accepted: 24 March 2014 - Published: 19 May 2014

\begin{abstract}
We investigate the magnetic signature of ultramafic seafloor in the eastern part of the Southwest Indian Ridge (SWIR). There, detachment faulting, continuous over $11 \mathrm{Myr}$, exhumed large areas of mantle-derived rocks. These exhumed mantle domains occur in the form of a smooth rounded topography with broad ridges locally covered by a thin highly discontinuous volcanic carapace. We present high-resolution data combining deep-tow magnetics, sidescan sonar images and dredged samples collected within two exhumed mantle domains between $62^{\circ} \mathrm{E}$ and $65^{\circ} \mathrm{E}$. We show that, despite an ultra-slow spreading rate, volcanic areas within robust magmatic segments are characterized by well-defined seafloor spreading anomalies. By contrast, the exhumed mantle domains, including a few thin volcanic patches, reveal a weak and highly variable magnetic pattern. The analysis of the magnetic properties of the dredged samples and careful comparison between the nature of the seafloor, the deep-tow magnetic anomalies and the seafloor equivalent magnetization suggest that the serpentinized peridotites do not carry a sufficiently stable remanent magnetization to produce seafloor spreading magnetic anomalies in exhumed mantle domains.
\end{abstract}

\section{Introduction}

The eastern part of the ultra-slow-spreading Southwest Indian Ridge (SWIR) is among the deepest parts of the oceanic ridge system and represents a melt-poor end-member for this system (Karson et al., 1987; Cannat et al., 1999; Cannat et al., 2008). In this region, crustal accretion differs from the conventional seafloor spreading scheme as it occurs at about a $14 \mathrm{~mm} \mathrm{a}^{-1}$ full spreading rate (Patriat et al., 1997) in the form of magmatic but also non-magmatic processes (Cannat et al., 2006). In the past two decades, numerous papers have revealed the presence of exhumed mantle-derived rocks in the oceanic domain (Cannat et al., 1992; Cannat et al., 1995) but mechanisms leading to the formation of such a peculiar seafloor remain poorly understood. Although it has been proposed that long-lived detachment faults could often accommodate $50 \%$ to $70 \%$ (Buck et al., 2005) of the plate separation over $\sim 3 \mathrm{Myr}$, the eastern part of the SWIR is currently the only known oceanic area where continuous mantle exhumation over 11 Myr has been observed (Sauter et al., 2013). There, detachment faulting associated with no or very little volcanic activity seems to be the only process producing the oceanic lithosphere. The resulting seafloor, called "smooth seafloor" (Cannat et al., 2006), is thought to be formed by alternating "flip flop" exhumation faulting (Sauter et al., 2013), a mechanism that has also been proposed to explain the formation of the "zone of exhumed continental mantle" (Reston and McDermott, 2011) observed along the 
ocean-continent transition (OCT) in the western Iberia margin.

The conventional understanding of seafloor magnetic anomalies is that their source mainly resides in an upper crustal layer of effusive volcanic rocks (e.g., Harrison, 1987). However, studies at slow-spreading ridges have also suggested a contribution from other lithologies, such as gabbros and serpentinized peridotites (Pariso and Johnson, 1993; Nazarova, 1994; Oufi et al., 2002). A better understanding of the variability of the amplitude of the magnetic anomalies over exhumed mantle domains is required to assess the validity of kinematic reconstructions at both ultra-slow-spreading mid-oceanic ridges and magma-poor passive margin systems. In this paper, we investigate the magnetic signal over large exhumed mantle domains in the easternmost part of the SWIR. We present results from a deep-tow geologicalgeophysical survey over two areas between $62^{\circ} \mathrm{E}$ and $65^{\circ} \mathrm{E}$ combining magnetic data, geological mapping from sidescan sonar images (from Sauter et al., 2013) and dredge sampling. We examine the magnetic signature over a 0 to $11 \mathrm{Ma}-$ old smooth seafloor. The aim is to better understand the complexity of the marine magnetic anomalies observed above the serpentinized mantle rocks exhumed at mid-oceanic ridges (Sauter et al., 2008). Finally we discuss the implications of our findings for the understanding of exhumed mantle domains at OCTs of magma-poor rifted margins and the origin and significance of broad zones of chaotic magnetic patterns are discussed (Russell and Whitmarsh, 2003; Sibuet et al., 2007; Bronner et al., 2011; Tucholke and Sibuet, 2012; Bronner et al., 2012).

\section{Geological background}

A significant change in the Africa-Antarctica relative plate motion occurred between magnetic anomaly C8 and C6 $(\sim 24 \mathrm{Ma}$ ago $)$ resulting in a $50 \%$ decrease in full spreading rate at the SWIR, from slow $\left(24 \mathrm{~mm} \mathrm{a}^{-1}\right)$ to ultra-slow (14 $\mathrm{mm} \mathrm{a}^{-1}$; Patriat et al., 2008). This ultra-slow spreading rate varies only slightly along the $7700 \mathrm{~km}$ ridge axis. By contrast, compilations of geophysical and geochemical data along the SWIR reveal large-scale variations of the density and thermal structure of the axial region (e.g., Cannat et al., 1999; Georgen et al., 2001; Cannat et al., 2008). Unusually cold mantle temperatures and relatively thin crust at the eastern SWIR, in particular, east of the Melville transform fault $\left(60^{\circ} 45^{\prime} \mathrm{E}\right)$, are supported by evidence on-axis (Cannat et al., 2008) as well as off-axis (Sauter et al., 2011). An eastward decreasing crustal thickness and/or mantle temperature is inferred from gravity data along the SWIR axis (Cannat et al., 1999). It is further supported by geochemical proxies for the degree of partial melting in the mantle (e.g., average composition of the sodium content of axial basalts derived from the axial zone) suggesting a progressive eastward decrease of the ridge melt supply (Meyzen et al., 2003; Seyler et al., 2003;
Cannat et al., 2008). Thin crust in the easternmost part of the SWIR ( $3.7 \mathrm{~km}$ average crustal thickness) is also confirmed by seismic data (Minshull et al., 2006).

The easternmost part of the SWIR axial valley displays a ridge segmentation that differs significantly from what is observed at faster-spreading ridges such as the Mid-Atlantic Ridge (MAR). High-relief ridge segments ( $>3000 \mathrm{~m}$ high) are linked by $>100 \mathrm{~km}$-long, deep axial sections with almost no volcanic activity (Sauter et al., 2004). The ridge flanks display the widest known areas of seafloor with no evidence of a volcanic upper crustal layer (Cannat et al., 2006). This non-volcanic ocean floor has no equivalent at fasterspreading ridges. Cannat et al. (2006) called this seafloor "smooth seafloor" because it occurs in the form of broad ridges with a smooth, rounded topography and lacks the telltale hummocky morphologies of submarine volcanism. This non-volcanic seafloor also lacks the corrugations identified on oceanic core complexes at slow-spreading ridges. A few dredges in the axial valley from earlier cruises suggested that the smooth seafloor is associated with outcrops of serpentinized mantle-derived peridotites (Cannat et al., 2006). Offaxis dredges and side-scan sonar imagery confirmed that this smooth seafloor is almost entirely composed of seawateraltered mantle rocks resulting in serpentinized peridotites that were brought to the surface by large detachment faults on both sides of the ridge axis (Sauter et al., 2013). The detachment faults are thought to repeatedly flip polarity and have accommodated nearly $100 \%$ of the plate divergence for the last $10 \mathrm{Myr}$ (Sauter et al., 2013).

\section{Acquisition and processing of magnetic data}

Data presented in this paper were collected during an R/V Marion Dufresne cruise MD183 in October 2010 using a $30 \mathrm{kHz}$ side-scan sonar and a three component (3C) magnetometer carried by the Towed Ocean Bottom Instrument (TOBI; Flewellen et al., 1993). The survey was divided into two corridors, a western corridor from 62 to $63^{\circ} \mathrm{E}$ and an eastern corridor from 64 to $65^{\circ} \mathrm{E}$. Seven profiles were acquired in the western corridor, all above exhumed mantle, and four profiles were acquired in the eastern corridor, one above volcanic seafloor and three above exhumed mantle rocks (Fig. 1). TOBI was operated at altitudes of $250-700 \mathrm{~m}$ above the seafloor at a tow speed of about 2 knots.

The three component magnetic data were corrected for the magnetization of the TOBI vehicle using a scalar calibration procedure (Bronner et al., 2013). The magnetic effect of the vehicle was removed with no recourse to its attitude (pitch, roll or heading) as it is commonly done (Isezaki, 1986; Korenaga, 1995), but only using the output of the magnetometer and a model of the scalar intensity of the geomagnetic field (e.g., International Geomagnetic Reference Field IGRF). Calibration parameters were thus free from orientation bias (see Bronner et al., 2013) and the estimation of both 


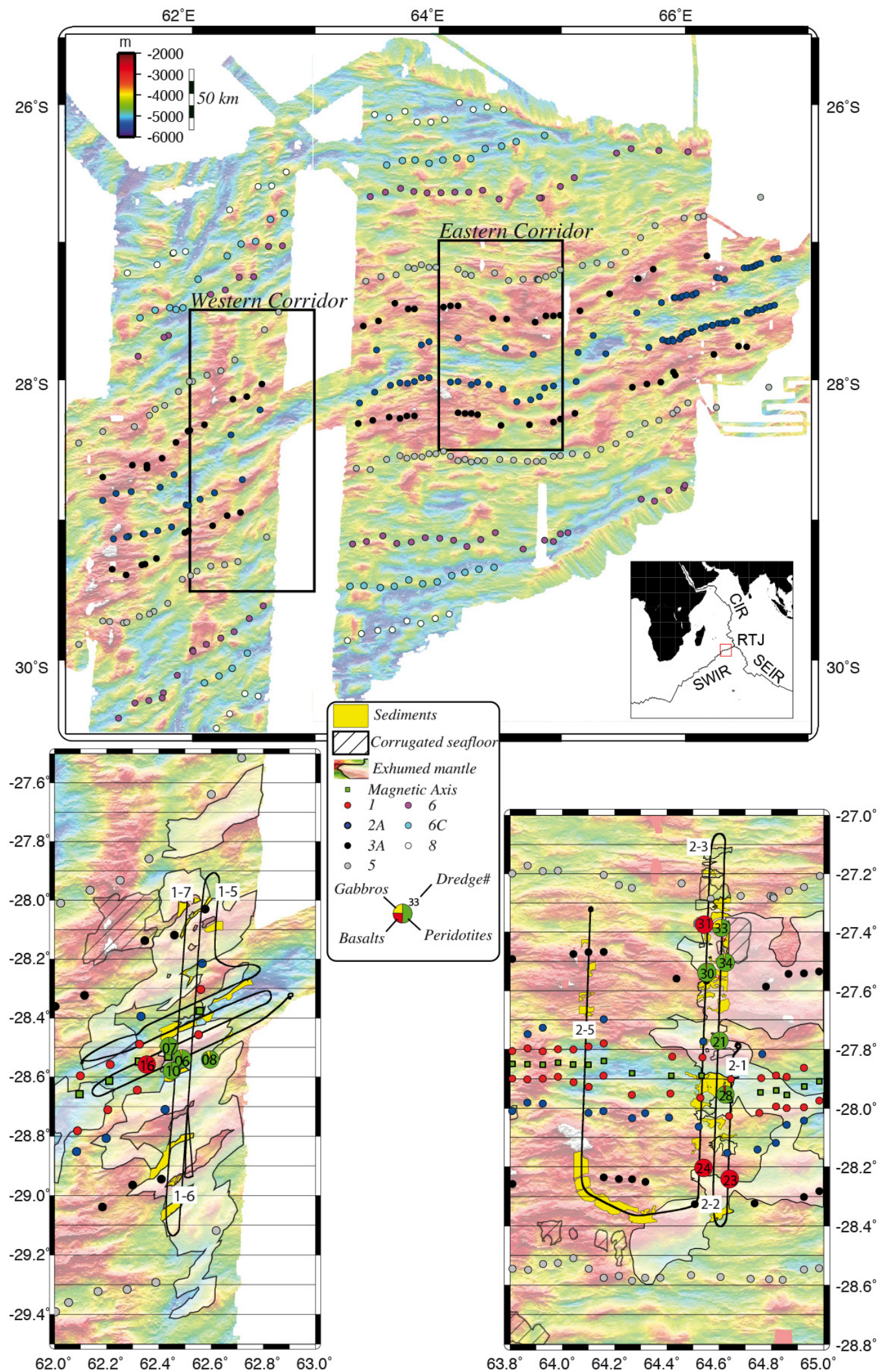

Figure 1. Bathymetric map with the location of the two survey areas (western and eastern corridor). Magnetic anomaly picks are from Sauter et al. (2008). The nature of the seafloor was deduced either from the side-scan images when available (Sauter et al., 2013) or from the multibeam bathymetric data (Cannat et al., 2006). The dredge numbers and the proportion of rocks by weight shown as pie charts are from Sauter et al. (2013). We have only shown the dredges for which we measured the magnetic properties (see Table 1 and Figs. 3 and 5). 
Table 1. Magnetic properties of the dredge samples. Highly serpentinized peridotites are more than $90 \%$ serpentinized and medium serpentinized peridotites are 75 to $90 \%$ serpentinized. Natural remanent magnetization (NRM), magnetic susceptibility and Koenigsberger ratio $(Q)$ are plotted in Fig. 5.

\begin{tabular}{|c|c|c|c|c|c|}
\hline Dredge \# & Observations & Susceptibility (SI) & $\operatorname{NRM}\left(\mathrm{A} \mathrm{m}^{-1}\right)$ & Koenigsberger ratio $(Q)$ & Total magnetization $\left(\mathrm{A} \mathrm{m}^{-1}\right)$ \\
\hline DR6 & Medium serpentinized peridotite & 0.016 & 0.70 & 1.29 & 1.25 \\
\hline DR6 & Medium serpentinized peridotite & 0.018 & 0.66 & 1.09 & 1.26 \\
\hline DR7 & Medium serpentinized peridotite & 0.016 & 0.79 & 1.47 & 1.32 \\
\hline DR7 & Highly serpentinized peridotite & 0.045 & 3.47 & 2.31 & 4.98 \\
\hline DR7 & Highly serpentinized peridotite & 0.031 & 1.25 & 1.20 & 2.29 \\
\hline DR7 & Medium serpentinized peridotite & 0.014 & 0.09 & 0.19 & 0.55 \\
\hline DR8 & Highly serpentinized peridotite & 0.002 & 0.08 & 1.56 & 0.13 \\
\hline DR8 & Highly serpentinized peridotite & 0.052 & 0.52 & 0.30 & 2.25 \\
\hline DR8 & Highly serpentinized peridotite & 0.037 & 0.70 & 0.57 & 1.92 \\
\hline DR8 & Highly serpentinized peridotite & 0.054 & 1.84 & 1.03 & 3.62 \\
\hline DR10 & Medium serpentinized peridotite & 0.028 & 2.12 & 2.29 & 3.04 \\
\hline DR10 & Medium serpentinized peridotite & 0.005 & 0.28 & 1.56 & 0.46 \\
\hline DR10 & Medium serpentinized peridotite & 0.028 & 0.97 & 1.03 & 1.91 \\
\hline DR10 & Medium serpentinized peridotite & 0.015 & 1.24 & 2.47 & 1.74 \\
\hline DR16 & Highly serpentinized peridotite & 0.058 & 0.92 & 0.48 & 2.86 \\
\hline DR16 & Highly serpentinized peridotite & 0.050 & 2.28 & 1.37 & 3.94 \\
\hline DR16 & Highly serpentinized peridotite & 0.070 & 1.88 & 0.81 & 4.19 \\
\hline DR21 & Highly serpentinized peridotite & 0.007 & 0.30 & 1.25 & 0.54 \\
\hline DR28 & Highly serpentinized peridotite & 0.020 & 0.64 & 0.95 & 1.31 \\
\hline DR28 & Highly serpentinized peridotite & 0.016 & 0.35 & 0.63 & 0.91 \\
\hline DR28 & Highly serpentinized peridotite & 0.028 & 0.52 & 0.54 & 1.49 \\
\hline DR28 & Highly serpentinized peridotite & 0.037 & 2.47 & 1.98 & 3.71 \\
\hline DR30 & Highly serpentinized peridotite & 0.013 & 1.94 & 4.52 & 2.36 \\
\hline DR30 & Highly serpentinized peridotite & 0.014 & 0.43 & 0.88 & 0.92 \\
\hline DR33 & Highly serpentinized peridotite & 0.005 & 0.09 & 0.50 & 0.26 \\
\hline DR34 & Highly serpentinized peridotite & 0.026 & 0.25 & 0.29 & 1.14 \\
\hline DR34 & Highly serpentinized peridotite & 0.020 & 0.17 & 0.25 & 0.84 \\
\hline DR34 & Highly serpentinized peridotite & 0.041 & 2.44 & 1.77 & 3.82 \\
\hline DR34 & Highly serpentinized peridotite & 0.043 & 7.98 & 5.42 & 9.45 \\
\hline DR16 & Basalt & 0.002 & 4.60 & 67.94 & 4.67 \\
\hline DR16 & Basalt & 0.001 & 4.18 & 96.31 & 4.22 \\
\hline DR16 & Basalt & 0.002 & 4.39 & 82.96 & 4.44 \\
\hline DR31 & Phe basalt & 0.001 & 2.26 & 49.80 & 2.31 \\
\hline DR31 & Phe basalt & 0.001 & 1.88 & 39.03 & 1.93 \\
\hline DR31 & Aph basalt & 0.002 & 0.09 & 1.50 & 0.15 \\
\hline DR31 & Aph basalt & 0.002 & 0.11 & 2.08 & 0.16 \\
\hline DR23 & Aph basalt & 0.001 & 1.38 & 41.34 & 1.41 \\
\hline DR23 & Aph basalt & 0.001 & 2.04 & 67.45 & 2.07 \\
\hline DR23 & Aph basalt & 0.001 & 0.83 & 16.81 & 0.88 \\
\hline DR24 & Aph basalt & 0.003 & 5.18 & 60.46 & 5.27 \\
\hline DR24 & Aph basalt & 0.002 & 0.17 & 2.58 & 0.24 \\
\hline DR22 & Ferro-gabbro & 0.009 & 0.26 & 0.82 & 0.58 \\
\hline DR22 & Ferro-gabbro & 0.015 & 0.16 & 0.31 & 0.67 \\
\hline DR33 & Altered ferro-gabbro & 0.003 & 1.00 & 10.05 & 1.10 \\
\hline DR33 & Altered ferro-gabbro & 0.000 & 1.75 & 164.81 & 1.76 \\
\hline DR34 & Gabbro & 0.002 & 0.04 & 0.55 & 0.12 \\
\hline DR34 & Gabbro & 0.004 & 0.25 & 1.71 & 0.39 \\
\hline DR34 & Ferro-gabbro & 0.052 & 2.64 & 1.48 & 4.42 \\
\hline DR34 & Ferro-gabbro & 0.052 & 2.88 & 1.64 & 4.64 \\
\hline DR34 & Altered ferro-gabbro & 0.025 & 0.37 & 0.44 & 1.21 \\
\hline DR34 & Altered-ferro-gabbro & 0.077 & 4.63 & 1.78 & 7.24 \\
\hline
\end{tabular}


instrumental miscalibration and removal of the vehicle effect were performed simultaneously. In order to constrain the calibration parameters as much as possible, the geomagnetic field was recorded in a $360^{\circ}$ calibration loop in a region of the SWIR where the field was assumed to be constant, and with the most variable attitude possible of the vehicle. Variations of pitch and roll were obtained by successively hauling in and paying out the wire. The magnetic signal of the vehicle was found to be about $3500 \mathrm{nT}$ and reduced to less than $10 \mathrm{nT}$ after calibration. Magnetic data presented in this paper were only corrected via these calibration parameters; no filtering was applied and the quality of the processing was confirmed through a comparison between upward continued data and sea surface proton magnetometer profiles (Bronner et al., 2013).

As magnetic data were acquired along uneven altitudes, we used an equivalent source approach (Dampney, 1969) to invert the magnetic profiles and to perform an upward continuation to a constant observation level. We assume that the measured magnetic anomalies are due to uniformly magnetized dipoles that extend infinitely perpendicular to the spreading and profile direction. The so-called "equivalent layer" is draped on the bathymetry $500 \mathrm{~m}$ below the seafloor and magnetization directions are assumed to be parallel to the Earth's magnetic field $\left(-60^{\circ}\right.$ inclination and $-30^{\circ}$ declination in this area of the SWIR). Magnetization of the dipoles is then computed in the spatial domain as a single linear inversion to the distances between dipoles and observation points (Bronner et al., 2013). Once the magnetization is obtained, upward continuation is performed by computing the magnetic field on the basis of the equivalent sources at the desired observation level (Fig. 2). Over the volcanic seafloor, we assume that a standard homogeneous $500 \mathrm{~m}$ layer accounts for the observed magnetic anomalies (e.g., Gee and Kent, 2007). The inferred magnetization values are thus divided by the assumed dipole spacing and layer thickness to yield units of ampere per meter. Magnetizations above exhumed mantle areas are calculated in the same way, although we have little knowledge about the source layer thickness there. These magnetizations have thus to be treated with caution and are only presented as a comparison to the volcanic seafloor. Variations in inverted magnetizations over exhumed mantle domains could either result from changes of intrinsic magnetization or from variability in the source thickness.

To be consistent, all deep-tow magnetic anomaly profiles displayed in Fig. 2 are continued upward to a constant level of $1200 \mathrm{~m}$ b.s.l. (shallowest depth of the TOBI during the whole survey). Two-dimensional magnetic anomaly profiles are represented above seafloor topography on which geological interpretations from side-scan images (from Sauter et al., 2013) are superimposed (Fig. 2). As the profiles are about $6 \mathrm{~km}$ apart (width of the TOBI side-scan swath) we do not perform 3-D inversion or magnetic mapping; instead, we calculate magnetizations along profiles and display them as colored strips of arbitrary width superimposed on the bathymetry (Fig. 3). Identification of magnetic anomalies are based on Sauter et al. (2008).

The TOBI $30 \mathrm{kHz}$ side-scan sonar provides 3 m-resolution acoustic images of the seafloor. Interpretation of the reflectivity combined with results from dredges leads to the distinction between three types of seafloor (see Sauter et al., 2013): (1) volcanic seafloor, corresponding to highly reflective surfaces composed of volcanic cones $(<200 \mathrm{~m}$ across $)$ and sinuous scarps characteristic of the presence of pillow lava flows; (2) smooth seafloor, corresponding to smooth and homogeneous topography associated with low and uniform reflectivity; and (3) corrugated seafloor (Cannat et al., 2006), associated with striations comparable to the slip surfaces that are commonly observed at oceanic core complexes of the MAR (Cann et al., 1997). As the sedimentary cover is limited to small patches in this region, the nature of the seafloor below is extrapolated from the surrounding exposed rocks.

\section{Magnetic signal over volcanic seafloor: a seafloor spreading model}

Profile 2-5 was acquired between magnetic anomaly $\mathrm{C} 3 \mathrm{~A}$ on each flank (see Fig. 1) above an exclusively volcanic seafloor associated with a relatively thick crust suggested by low residual mantle Bouguer anomalies (RMBA $<20 \mathrm{mGal}$; Cannat et al., 2006). We use it as a reference to calibrate the spreading rate and identify the main polarity reversals. The inverted magnetization values reach around $10 \mathrm{~A} \mathrm{~m}^{-1}$ at the axis (resulting in a $\sim 500 \mathrm{nT}$ amplitude for the central anomaly; Figs. 2 and $3 \mathrm{~b}$ ) and $5 \mathrm{~A} \mathrm{~m}^{-1}$ off-axis. These values are in agreement with previous observations in this area (Searle and Bralee, 2007) and in another section of the SWIR near $58^{\circ} \mathrm{E}$ (Hosford et al., 2003). Despite the ultraslow spreading rate, the main magnetic blocks are well resolved (Figs. 2 and 3) and associated with relatively strong magnetic contacts.

Seafloor spreading anomalies are modeled using the software "MODMAG" developed by Mendel et al. (2005). A $14 \mathrm{mma}^{-1}$ uniform full spreading rate associated with a $500 \mathrm{~m}$-thick source layer draped over the topography and a $10 \mathrm{~A} \mathrm{~m}^{-1}$ magnetization on-axis decreasing to $5 \mathrm{~A} \mathrm{~m}^{-1}$ offaxis enables the reproduction of the main magnetic anomalies observed over the volcanic crust at profile 2-5 (Fig. 2). At such an ultra-slow spreading rate the identification of the seafloor spreading anomalies is more difficult than for fasterspreading ridges because reverse and normal polarity blocks may overlap. Therefore, a 0.7 contamination coefficient (Tisseau and Patriat, 1981) is used as a good compromise to both account for contamination between adjacent magnetic blocks with different polarity and preserve the small wavelength anomalies, such as anomaly C2 (Fig. 2; profile $2-$ 5). There is a reasonable fit between the observed magnetic anomaly profile and this forward model regarding the central Brunhes anomaly while southern anomaly C2A and northern 


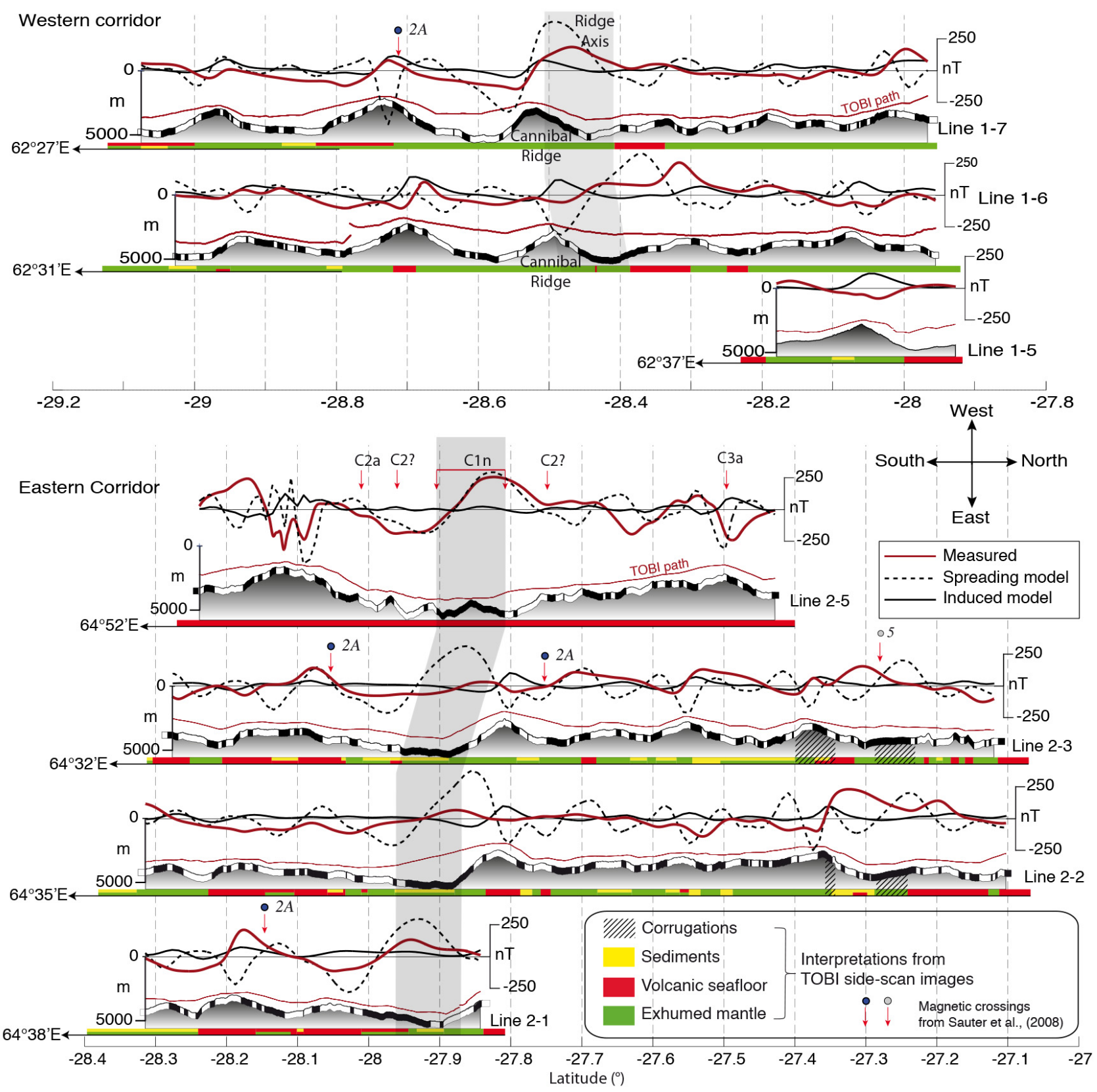

Figure 2. Two-dimensional magnetic profiles recorded within the two survey areas along the profiles shown in Fig. 1. Magnetic data (continuous red lines) have been continued upward to a depth of $1200 \mathrm{~m}$ below sea level. Broken lines correspond to the magnetic anomaly predicted by a $14 \mathrm{~mm} \mathrm{a}^{-1}$, seafloor spreading model calibrated on the volcanic seafloor (profile 2-5) with a $500 \mathrm{~m}$-thick source layer and a 10 and $5 \mathrm{~A} \mathrm{~m}^{-1}$ magnetization for the axial and off-axis blocks, respectively. The reversal pattern of the seafloor spreading model is superimposed on the bathymetry. Black solid lines correspond to a model based on a $2 \mathrm{~km}$-thick source layer for which an induced and uniform magnetization is applied $\left(1.5 \mathrm{~A} \mathrm{~m}^{-1}\right)$. Interpretations from the side-scan images are shown below the bathymetry profiles (from Sauter et al., 2013). The vertical grey area indicates the location of the axial valley.

anomaly $\mathrm{C} 3 \mathrm{~A}$ are in agreement with previous identifications on sea surface magnetic anomaly profiles (Sauter et al., 2008). Anomaly C2A is not clearly identified on the northern flank. This is consistent with observations from Searle and Bralee (2007) who showed that this polarity reversal was either smaller than predicted or missing in the northern flank in this area. We also suggest that anomaly $\mathrm{C} 2$ could account for the two small wavelength events observed on both sides of the central anomaly. 
(a)

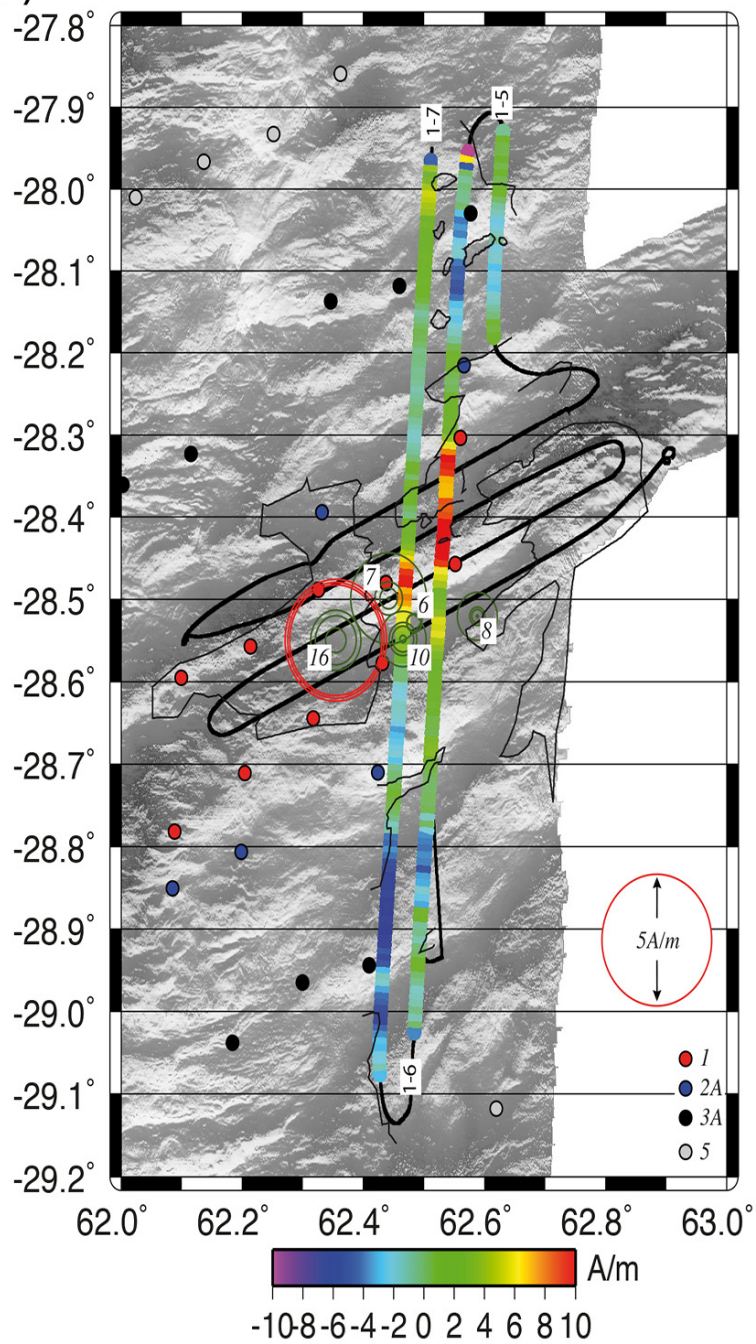

(b)

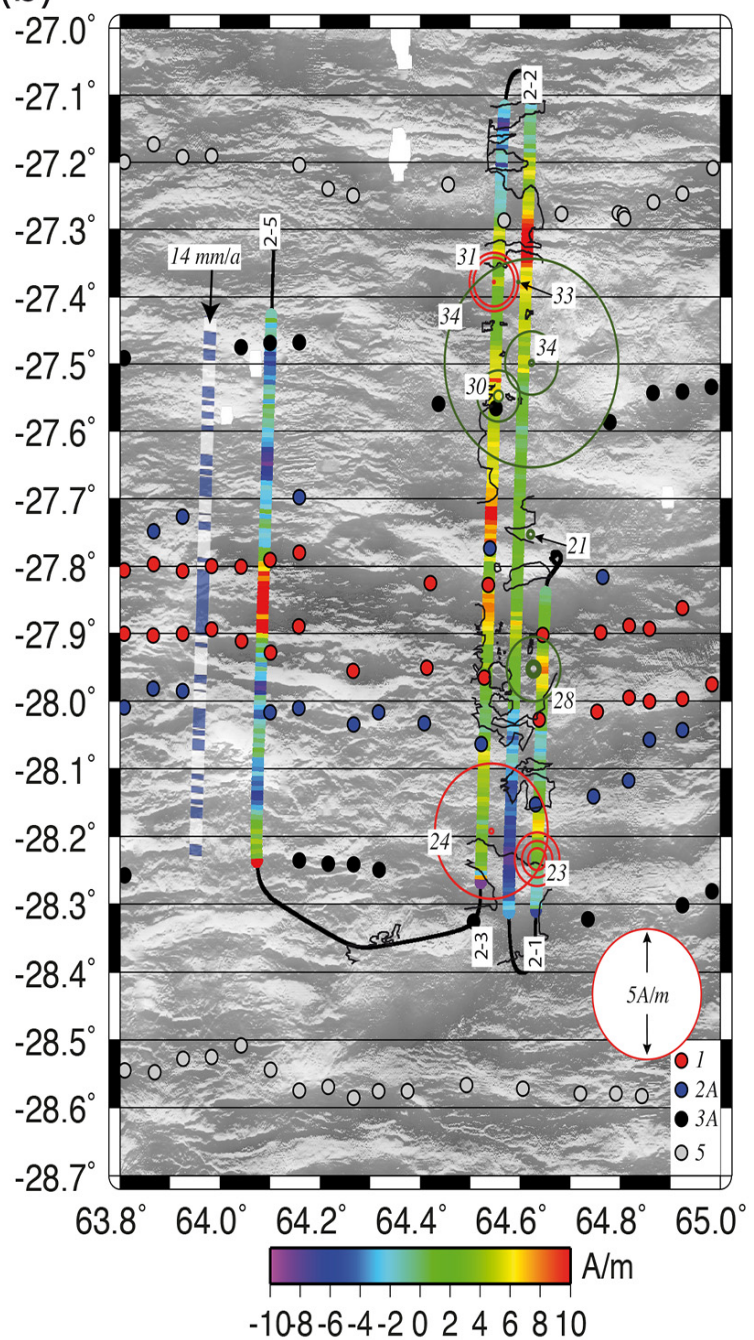

Figure 3. Inverted magnetization for the western (a) and eastern survey area (b). Colored strips show the calculated magnetization values along the magnetic-anomaly profiles (black lines). Shaded relief images are shown in background. Red circles are sized relatively to the Natural Remanent Magnetization (NRM) values of dredged basalts whereas green circles correspond to NRM values measured on dredged peridotites (see Table 1). The dredge number is shown in the white box near the circles. The thin black lines corresponding to the edges of the volcanic seafloor are from Sauter et al. (2013). Picking of magnetic anomalies is the same as in Fig. 1. A $14 \mathrm{~mm} \mathrm{a}^{-1}$ reversal pattern is superimposed for comparison in Fig. 3b.

\section{Magnetic signal over exhumed serpentinized mantle}

\subsection{The western corridor}

The western corridor extends between magnetic anomalies C3A (Cannat et al., 2006) and includes two 100 km-long north-south magnetic profiles $6 \mathrm{~km}$ apart (profiles $1-6$ and 1-7; Fig. 1) and one short ( $30 \mathrm{~km})$ profile that does not cross the axis (profile 1-5; Fig. 1). The magnetic data of the east-west profiles are not presented in this paper because the 2-D assumption used for the upward continuation and the computation of the magnetization is unreliable in that case.
Therefore, we only use the side-scan images from these eastwest lines to constrain the nature of the seafloor. Careful analysis of bathymetry, side-scan images and dredge samples suggests that the seafloor in this corridor is exclusively made of wide serpentinized peridotite ridges topped by thin ( $<100-200$ m-thick) volcanic patches (Sauter et al., 2013; Figs. 2 and 3). The axial valley is marked by an unconventional morphology comprising a $2000 \mathrm{~m}$-high peridotite ridge, called "Cannibal Ridge", that emerges from the axial domain (Fig. 2).

The axial magnetic anomaly is hardly visible in profile $1-$ 6 (Fig. 2) whereas a higher $(\sim 300 \mathrm{nT})$ amplitude anomaly is 
observed in profile 1-7 at the top of the Cannibal Ridge. Similarly, a few kilometers north of the ridge axis, a $\sim 150 \mathrm{nT}$ amplitude magnetic anomaly that is recorded in profile 16 is absent from profile $1-7$. Only one anomaly previously identified as anomaly C2A (Sauter et al., 2008) and located on top of the first ridge south of the axis is continuous between the two profiles (Fig. 2). On the inverted magnetization profiles (Figs. 3 and 4), an area of high magnetization (up to $10 \mathrm{~A} \mathrm{~m}^{-1}$ ) is located on the north flank of the Cannibal Ridge and is identified as the axial magnetic high (profile $1-7)$. To the east, in profile $1-6$, the same feature is shifted northward to the deeper part of the axial valley. Off-axis, the magnetization is weak and associated with smooth magnetic contacts.

\subsection{The eastern corridor}

The eastern corridor (profiles 2-1, 2-2 and 2-3) shows a more complex morphological structure. It is at the transition from an exclusively volcanic seafloor in the west to a wide exhumed mantle domain in the east. It is characterized by a series of broad, rounded serpentinized peridotite ridges south of the axial valley, whereas a shallower and flatter topography prevails to the north. The northern end of the survey (near anomaly C5, north of $27.37^{\circ} \mathrm{S}$; Figs. 2, 3 and 4) shows two corrugated surfaces where the recovery of more frequent gabbroic rocks (Sauter et al., 2013) associated with a low RMBA ( $<20 \mathrm{mGal}$; Sauter et al., 2008) suggest more robust magmatic activity. Apart from this particular area and some thin (less than $300 \mathrm{~m}$-thick), small volcanic patches observed within the axial domain and at the top of some serpentinized peridotite ridges, the eastern corridor is formed almost exclusively of smooth exhumed mantle surfaces associated with very little magmatic supply. Moreover, evidence was found that the $\sim 2400 \mathrm{~m}$-high, $25^{\circ}$-south-dipping northern axial valley wall corresponds to the footwall of a recent large detachment fault cutting the earlier sedimented smooth inner floor and accommodating the plate separation (Sauter et al., 2013).

What has been interpreted as the central magnetic anomaly (Sauter et al., 2008) goes from a very low magnetic anomaly $(<100 \mathrm{nT}$ amplitude) above the detachment footwall in the west (profiles 2-3 and 2-2) to a slightly stronger anomaly of $\sim 250 \mathrm{nT}$ in the deeper part of the axial valley to the east (profile 2-1; Figs. 2 and 3). Similarly, on the south flank, the anomaly identified as $\mathrm{C} 2 \mathrm{~A}$ in profile $2-1$ is shifted $10 \mathrm{~km}$ north in profile 2-3 and is almost missing from profile 2 2. On the conjugate plate to the north, in between the ridge axis and anomaly $\mathrm{C} 5$, the magnetic signal is also flat with no clear seafloor spreading anomalies and no lateral continuity; only anomaly $\mathrm{C} 5$ seems resolvable and quite continuous. The inverted magnetization profiles (Fig. 3) show a similar pattern to those from the western corridor: a very flat magnetization associated with smooth magnetic contacts over the exhumed mantle areas. Only anomaly C5 and very local mag- netization highs, such as north of the ridge axis in profile $2-3$, are observed.

\subsection{Magnetic structure of the different types of seafloor}

At the ridge axis, the magnetization of the exhumed mantle is generally low $\left(<5 \mathrm{~A} \mathrm{~m}^{-1}\right)$, but it can be locally significant (e.g., up to $10 \mathrm{~A} \mathrm{~m}^{-1}$ in profile 1-7) and shows ill-defined magnetic contrasts compared to the volcanic areas. No clear wide central block is observed in the western corridor as large magnetized blocks are alternatively observed above the Cannibal Ridge (profile 1-7; Fig. 4) or in the deeper part of the axial valley (profile 1-6; Fig. 4). Similarly, the central block is virtually absent within the eastern corridor; a small anomaly with slightly larger magnetization (up to $8 \mathrm{~A} \mathrm{~m}^{-1}$ ) is shifting from the southern (profile 2-1; Fig. 4) to the northern axial valley wall (profile 2-3; Fig. 4). Off-axis, the exhumed mantle surfaces show no evidence for volcanic material (e.g., north side of profile 2-2; Fig. 4) and are characterized by low magnetizations (mostly $<2 \mathrm{~A} \mathrm{~m}^{-1}$ ) without any clear continuous magnetic anomaly from one profile to the other.

Apart from profile 2-5 showing large amplitude magnetizations, locally higher magnetization cannot be associated with volcanic seafloor both at the axis and on the flanks. The presence of extrusive rocks may, in some places, account for a higher magnetization but there is no unequivocal link. For instance, although a lava flow is identified just north of the Cannibal Ridge on both profiles 1-7 and 1-6 (Fig. 2), larger magnetization values are only observed on the eastern profile (profile 1-6; Figs. 3 and 4). Similarly, although relatively higher magnetizations (up to $10 \mathrm{~A} \mathrm{~m}^{-1}$ ) may be related to the proximity of the small volcanic patch north of the axial valley wall (profile 2-3), the few volcanic patches observed south of the axis of the western corridor do not produce any significant magnetization $\left(<+/-2 \mathrm{~A} \mathrm{~m}^{-1}\right.$ along profiles $2-$ 2 and 2-3; Fig. 4)

The corrugated surfaces observed at the northern end of profiles 2-2 and 2-3 are associated with stronger magnetizations (up to $10 \mathrm{~A} \mathrm{~m}^{-1}$ ) and a continuous magnetic anomaly identified as the anomaly $\mathrm{C} 5$.

\section{Magnetic properties of the dredged samples}

In order to have a better understanding of the magnetic behavior of the different rock bodies in the area, natural remanent magnetization (NRM) and magnetic susceptibility $(K)$ were measured on 12 basalt, 29 peridotite and 10 gabbro samples dredged in the two survey areas (Fig. 1 and Table 1). The magnetic susceptibility is an indication of the ability of a rock sample to acquire an induce magnetization whereas NRM is a direct measurement of thermoremanence. The susceptibility is plotted against the remanence for all measured samples (Fig. 5a). Two distinct trends are observed: a basalt 


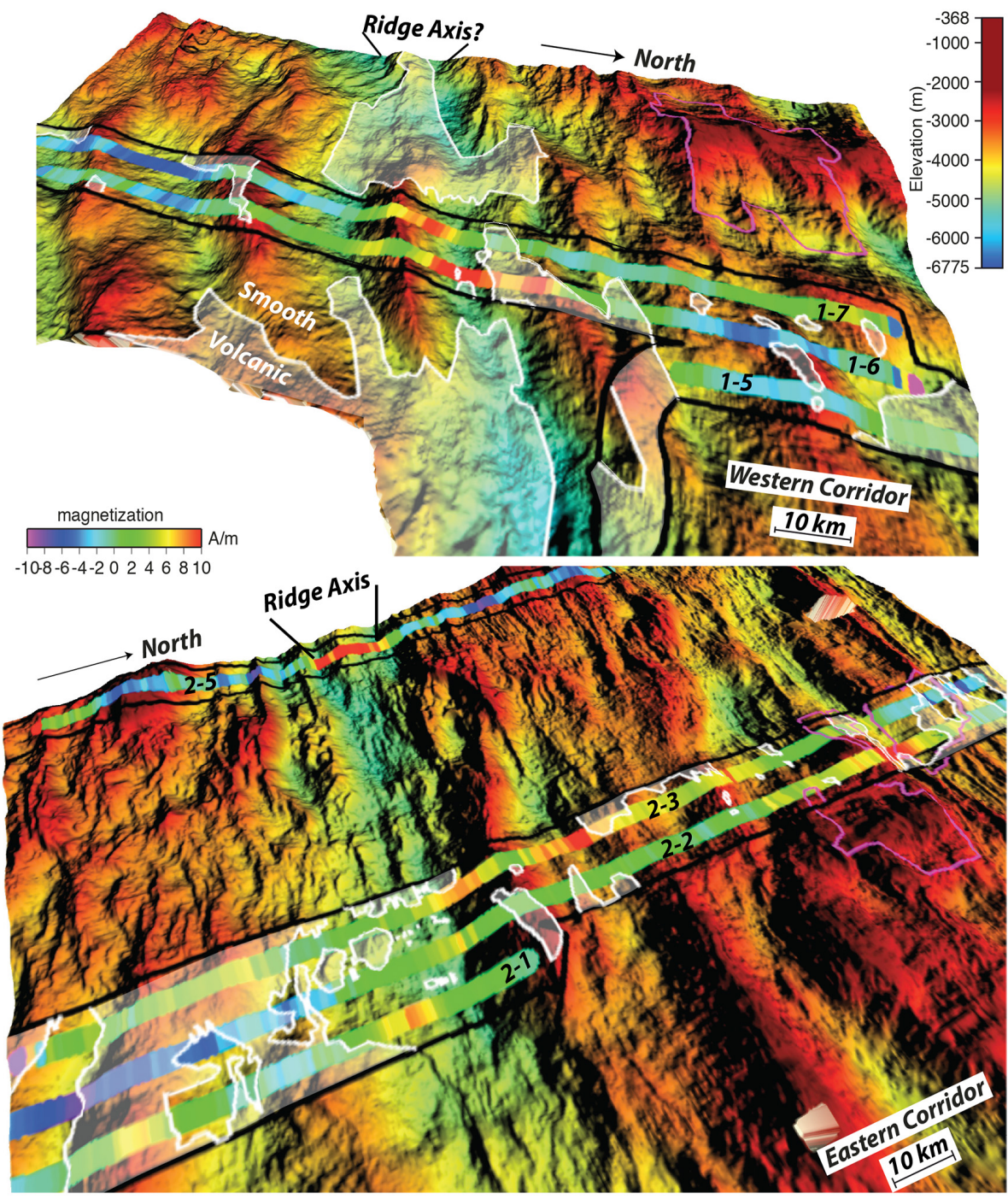

Figure 4. Three-dimensional bathymetric view of the two survey areas. The inverted magnetization (colored strips) and the edges (from Sauter et al., 2013) of both the corrugated surfaces (purple lines) and the volcanic seafloor (white faded areas) are draped on the multibeam bathymetric map. The magnetization scale is the same for the two survey areas. The black lines indicate the edges of the TOBI side-scan swath.

trend with samples having low susceptibilities even when they exhibit high NRMs and a peridotite trend regrouping samples having susceptibilities increasing significantly with increasing NRMs (Fig. 5a). Indeed some dredged peridotites have a NRM comparable to basaltic rocks (up to $8 \mathrm{~A} \mathrm{~m}^{-1}$ ), but for peridotites these high values are always associated with high susceptibility ( $K$ up to 0.07 International System of Units (SI)). Gabbros tend to fall in the peridotite trend with some exceptions. The Koenigsberger ratio is expressed as $Q=\mathrm{NRM} / K \cdot H$ (with $H$ being the magnetic field strength at the site) and is indicative of the balance between remanent vs. induced magnetization for each sample. Results are plotted in Fig. 5b; lower Koenigsberger ratios are observed for peridotites and gabbros and half of these samples have a Koenigsberger ratio below 1 indicating their magnetiza- tion is dominantly induced. This result is in agreement with previous results at the MAR (Oufi et al., 2002). Basalts always show a ratio above 1 , with a mean of $\sim 40$, indicating the strong dominance of remanent over induced magnetization. Beyond these sharp, lithologically based magnetic differences it is difficult to identify any finer-scale magnetic behavior which could be linked to the magnetic profile. First, both NRMs and susceptibilities are highly variable even for a set of samples with the same lithology collected within the same dredge (see Table 1). Features in the magnetic profile are thus not easily related to rock magnetic measurements. As an example, the strongest magnetized peridotite samples (i.e., with the higher total magnetization) were recovered within a short lateral distance of each other in the middle of the north side of profiles 2-2 and 2-3 (Fig. 3). However, 
(a)

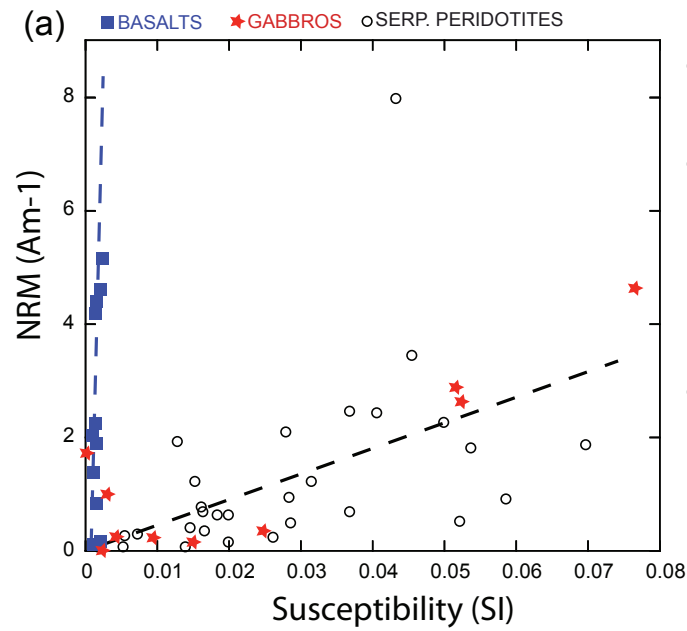

(b)

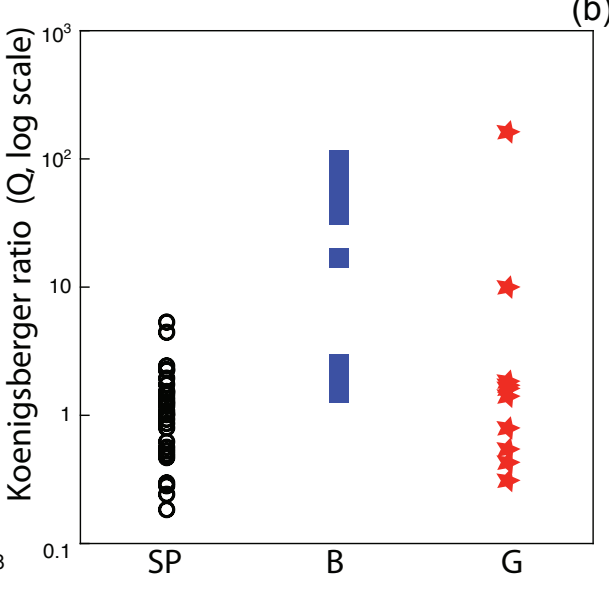

Figure 5. (a) Natural remanent magnetization (NRM) from dredged peridotites, basalts and gabbros as a function of the magnetic susceptibility $(K)$. (b) Koenigsberger ratio $(Q)$ for serpentinized peridotites (SP), basalts (B) and gabbros (G). Note that $Q$ has a logarithmic scale.

such a high magnetization is not recorded by the deep-tow magnetic data (Fig. 3), suggesting that either the magnetized source layer is thin or that high magnetizations occur only punctually, suggesting that such magnetizations are limited to small areas that cannot be detected by the deep-tow magnetometer.

\section{Forward modeling}

Seafloor spreading magnetic anomalies were identified along sea surface profiles over domains that lack a volcanic upper crustal layer in the easternmost part of the SWIR (Sauter et al., 2008), suggesting that other sources may play a significant role in preserving the Earth's magnetic field polarity. Along both the MAR and the SWIR, serpentinized peridotites have been suspected of carrying "more positive" magnetization amplitudes in areas of thin crust (Hosford et al., 2003; Tucholke et al., 2008). This observation is supported by the Koenigsberger ratio of the SWIR serpentinized peridotites, which is often less than 1 . This shows that, unlike basaltic rocks, induced magnetization may be significant for these rocks. We therefore perform two different kinds of forward modeling in order to test the contribution of volcanic rocks versus serpentinized peridotites: one based on a $500 \mathrm{~m}$ thick basaltic layer with a dominantly remanent magnetization, thus preserving the Earth's magnetic field polarity, and another based on an induced magnetized layer. We disregard the contribution of a lower crustal layer made of gabbroic rocks that is volumetrically scarce in the samples dredged within the exhumed mantle domains.

\subsection{Seafloor spreading model}

The seafloor spreading model calibrated on the volcanic seafloor (profile 2-5) was compared to the magnetic profiles acquired above the exhumed mantle domains of both eastern and western corridors. In the absence of a high-amplitude central anomaly, the axial Brunhes block was centered either at the bathymetric axis or underneath the central magnetic anomaly. Figure 2 shows the predicted magnetic anomaly along each across-axis profile (dashed black line). The parameters derived from profile $2-5$ give a poor fit to the observed magnetic field for the two corridors. The picked axial anomaly and anomaly $\mathrm{C} 2 \mathrm{~A}$ or $\mathrm{C} 3 \mathrm{~A}$ on sea surface magnetic profiles (Cannat et al., 2006) are not clearly observed on the deep-tow profiles over the exhumed mantle domains. Furthermore, the modeled anomaly $\mathrm{C} 5$ at the end of profiles $2-2$ and 2-3 appears to be shifted a few kilometers to the north with respect to the previously picked anomaly C5. This offset may be explained by either asymmetrical spreading, changes in spreading rate between anomalies $\mathrm{C} 3 \mathrm{~A}$ and $\mathrm{C} 5$ or a mislocation of the central Brunhes anomaly.

\subsection{Induced magnetized model}

To account for the unconstrained lateral and vertical variations in both intensity and direction of the remanent component of magnetization, we tested whether a uniform induced magnetized layer could solely account for the observed magnetic anomalies. As unaltered peridotites have a very weak susceptibility, the depth extent of serpentinization has to be determined. Seismic velocities in the exhumed mantle domains of the Iberian margin, as well as over slow-spreading ridges, suggest a high-serpentinization degree (greater than $75 \%$ ) in the first $2 \mathrm{~km}$ below the seafloor (Minshull et al., 


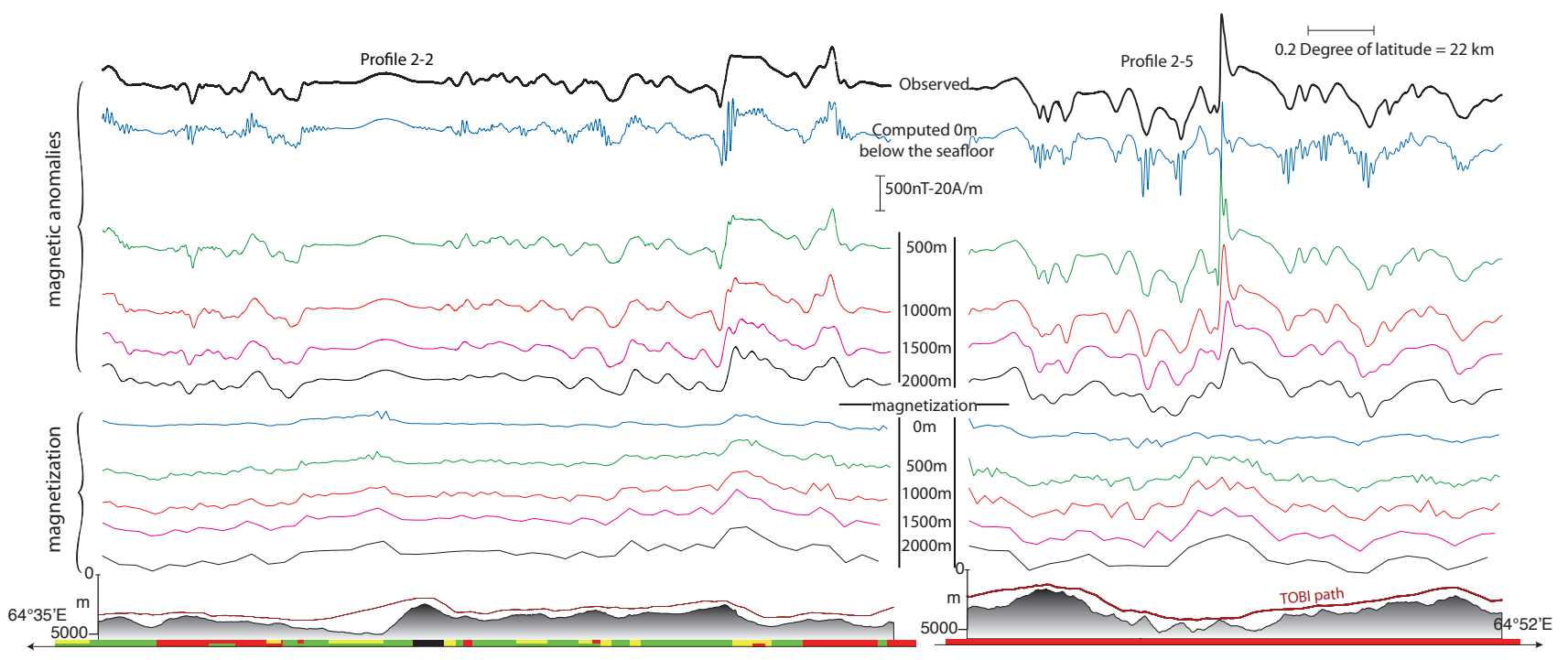

Figure 6. Comparison between the deep-tow observed magnetic field, along profiles $2-2$ and $2-5$, and the magnetic computed field along the TOBI path for different depths of inferred magnetized dipoles from 0 to $2000 \mathrm{~m}$ below the seafloor. In the lower panel, the magnetization solution is also reported along the same profiles for different depths. The shallowest and deepest dipoles lead respectively to the appearance of high frequency oscillations in the computed field and loss of resolution in both the computed field and the magnetization solution. The best compromise is found for dipoles located around $500 \mathrm{~m}$ below the seafloor for profile $2-5$ acquired above the volcanic crust and $1000 \mathrm{~m}$ for profile 2-2 collected above the exhumed mantle-derived rocks. A significant loss in resolution is observed for dipoles located below $1000 \mathrm{~m}$ in the case of the volcanic crust whereas both the computed field and the magnetization solution are quite well preserved up to $2000 \mathrm{~m}$ for the case of exhumed mantle seafloor.

1998; Chian et al., 1999; Dean et al., 2008). Thus, based on average NRM values measured on our dredge samples but also on serpentinites at Ocean Drilling Program (ODP) Holes 897D, 899B, 1070A and 1277 at the Iberia-Newfoundland margins (Zhao et al., 2001), we use a $1.5 \mathrm{~A} \mathrm{~m}^{-1}$ constant magnetization and $2 \mathrm{~km}$ constant thickness draped on the bathymetry as a source for the magnetic anomalies. In such models we assume that the whole magnetic signal is exclusively related to the seafloor topography.

The results are represented in Fig. 2 by the thin black continuous lines. In the western corridor, there is a poor fit between the synthetic and the observed magnetic anomaly along profile $1-5$ and especially in the axial valley of profile $1-6$. However, the agreement is better in profile $1-7$, even within the central domain. The only continuous anomaly between both profiles $1-6$ and $1-7$, picked as anomaly C2A by Sauter et al. (2008), is well-marked on both profiles. In the eastern corridors, where the areas of flat topography correspond to a flat observed magnetic field, the data are slightly comparable to the model except in the axial domain. Over the volcanic seafloor, the synthetic magnetic anomaly fits the observed magnetic anomaly poorly along profile $2-5$ in both axis and off-axis regions.

\section{Depth of the magnetic sources}

Usually, sources for marine magnetic anomalies are considered to be located in the extrusive upper part of the oceanic crust within a layer of constant thickness. Following Bronner et al. (2013), we use the equivalent layer method for the estimation of the thickness of this layer. Dampney (1969) has shown that the equivalent layer should be located within a certain range of depth below the measurement surface in order to avoid both the aliasing effect in the computed field and an ill-conditioned inversion matrix. In our case, we use the top seafloor as an upper bound because the altitude of the TOBI largely exceeds the data spacing $(\sim 10 \mathrm{~m})$ and we iteratively increase the depth of the equivalent layer until (1) the loss of short wavelength in both computed field and magnetization and/or (2) the appearance of oscillations in the solutions. Indeed, an equivalent source layer located too far below the measurement surface makes the matrix representing the distance between the equivalent sources and the observation points ill conditioned and the associated solution unreliable (Dampney, 1969). Therefore, we assume that this lower bound provides a first indication relative to the maximum depth of the "true" causative sources (i.e., the source layer thickness).

Applying this method to our survey, in the case of the "volcanic" profile (profile 2-5), the whole frequency content of the measured field was well retrieved for dipoles located around $500 \mathrm{~m}$ below the seafloor (Fig. 6). Shallower 
and deeper solutions lead respectively to the appearance of high frequency oscillations in the computed field and loss of resolution in the computed field and magnetization solution. By contrast, for the profiles acquired above the exhumed mantle domains (e.g., profile 2-2; Fig. 6), the weakness of the signal associated with a quasi absence of short wavelength anomalies allows reasonable solutions for both synthetic field and magnetization within a wider range of depth (up to $2000 \mathrm{~m}$ below the seafloor; Fig. 6).

As for any methods used to estimate the depth of magnetic sources, these results have to be treated with caution. The maximum depth of $500 \mathrm{~m}$ obtained above the volcanic seafloor is in agreement with the $500 \mathrm{~m}$-thick basaltic layer generally used to account for the marine magnetic anomalies at mid-oceanic ridges. This suggests that the 2-D hypothesis used here is reliable in the case of a 2-D homogeneous crustal accretion but we do not have much constraints on the magnetization structure of the exhumed mantle domains and the 2-D assumption may lead to some errors. The deeper solutions found for the sources in exhumed mantle domains mainly suggest that the short wavelength magnetic anomalies recorded above the volcanic areas are missing from the profiles acquired above serpentinized peridotites. This can be explained by deeper sources or by smoother magnetic contacts.

\section{Discussion}

\subsection{Seafloor spreading anomalies}

Because the shape of the marine magnetic anomalies strongly depends on the distance between two polarity reversals (i.e., frequency of polarity reversal versus spreading rate), the magnetic reversal pattern along ultra-slow-spreading ridges is often blurred. At the SWIR, geomagnetic reversals used for the resolution of spreading rates for the last $24 \mathrm{Ma}$ have often been restricted to long reversals of constant polarity, such as chrons C5 and C6, of about 1 Myr duration (Patriat et al., 2008). Moreover, in the eastern part of the SWIR, large variations in both crustal thickness (inferred from RMBA; Cannat et al., 2006) and lithology (from volcanic basalt to tectonized serpentinized peridotites) are associated with different modes of seafloor generation (volcanic extrusion or mantle exhumation). In addition to the ultra-slow spreading rate, these accretion modes are responsible for the complexity of the magnetic signal in this area. Short reversals such as $\mathrm{C} 3$ or $\mathrm{C} 2 \mathrm{~A}(\sim 0,5 \mathrm{Myr})$ are detectable only above thick volcanic crust associated with minor tectonic activity. Therefore, the identification of magnetic anomalies from sea surface magnetic profiles above smooth seafloor was mainly extrapolated from the surrounding volcanic areas (Sauter et al., 2008). However, the comparison of the mapping of exhumed mantle domains from multibeam bathymetric data at $150 \mathrm{~m}$ resolution and from TOBI images at $<10 \mathrm{~m}$ resolution reveals that sources of some of these magnetic anomalies identified along sea surface profiles were erroneously attributed to volcanic seafloor by Sauter et al. (2008) and may thus not be related to polarity changes of the Earth's magnetic field.

We are now able, with the high-resolution deep-tow data, to provide a precise analysis of the magnetic signal with respect to the geological nature of the seafloor. We confirm, as observed by Searle and Bralee (2007) in this region, that despite an ultra-slow spreading rate, marine magnetic anomalies are still well identifiable above volcanic seafloor. However, these identifications are much more difficult above the exhumed mantle domains where the magnetic pattern is highly variable from one profile to another. This is well illustrated in our studied corridors, where closely spaced magnetic profiles show a very heterogeneous magnetic signal. Except for anomaly C5, a simple seafloor spreading model (calibrated in profile 2-5) does not fit the magnetic anomaly pattern, even for the central anomaly (Fig. 2). Moreover, although the exhumed mantle domains are expected to be formed by asymmetrical detachment faulting, there is no evidence for lateral discontinuity between exhumed mantle areas and symmetrically accreted volcanic crust for which ages of accretion are quite well constrained (e.g., chrons younger than C5; Searle and Bralee, 2007). We thus suggest that both mantle exhumation and volcanic accretion are almost contemporary, leading to a reasonable lateral continuity (in terms of age) between different types of seafloor.

\subsection{Contribution of mantle-derived rocks}

The ferromagnetic behavior of serpentinized peridotites has been shown to be directly linked to the serpentinization process (Dunlop and Prévot, 1982). Magnetite is formed during serpentinization from the interaction between fluids and ferromagnesian minerals such as olivine and pyroxene. It has been suggested that a high degree of serpentinization (above $\sim 75 \%$ ) is necessary for the acquisition of both significant susceptibility and NRM (Oufi et al., 2002). However, highly variable NRMs are observed from one ODP site to another and also between samples drilled in a single ODP Hole (Oufi et al., 2002). In our study, a similar magnetic behavior is observed for the dredged peridotites. Values of NRM and susceptibility can be significant but are highly heterogeneous. The susceptibilities and NRM values in our dredged samples fall in the lower range of values reported for drilled abyssal peridotites (Oufi et al., 2002). Nevertheless, our samples show similar Koenigsberger ratios to those of drilled peridotites and they are strictly inferior to those expected for the extrusive upper layer of the oceanic crust (e.g., $\sim 50$ to 300; Marshall and Cox, 1971). Although peridotites outcropping at the seafloor are subject to low-temperature alteration, we consider that the magnetic properties of the dredged peridotites are representative of a magnetic source layer in the exhumed mantle domains. Based on our data we suggest that the high variability in NRM intensity combined with 
the large range of susceptibility and low Koenigsberger ratio make this layer of serpentinized peridotite magnetically weak and variable. This is in agreement with a recent study of serpentinized peridotite samples from both the Mirdita ophiolite and ocean drilling sites showing that strongly serpentinized $(>\sim 60 \%)$ peridotites have variable Koenigsberger ratios and are affected by randomly oriented, low-stability components that result in incoherent NRM directions on both site and regional scales (Maffione et al., 2014).

The presence of such a layer is confirmed by the highresolution deep-tow profiles, which display highly variable magnetic patterns from one profile to another, even where they are closely spaced. The magnetic anomalies observed above the exhumed mantle are weak $(<100 \mathrm{nT})$ and lack short wavelength anomalies, suggesting deeper magnetic sources than in the volcanic seafloor. Although it is possible to reproduce some magnetic patterns using an induced magnetic layer, the whole magnetic signal is not retrieved, especially within the axial domain. Similarly, the spreading model does not fit the observed data. It is thus likely that the sources combine both induced and remanent magnetization and vary from one local area to another.

Furthermore, in the western and more magmatic part of the SWIR $\left(54-56^{\circ} \mathrm{E}\right)$, a significant along-axis decrease in magnetization results in the disappearance of the magnetic reversal patterns in the deepest parts of ridge discontinuities (Sauter et al., 2004). This observation was linked to the thinning of the upper part of the oceanic crust due to a decreasing magmatic budget toward the segment ends. At the MAR $\left(13-15^{\circ} \mathrm{N}\right)$, it has also been shown that, within a highly complex accretion context combining detachment faulting and freshly erupted seafloor, the magnetic pattern could be significant in amplitude but highly heterogeneous on a scale of $\sim 5 \mathrm{~km}$ (Mallows and Searle, 2012), leading to difficulties in the identification of the spreading anomalies, even for the large Brunhes central block. This further suggests that a sufficiently homogeneous upper crust is required to produce well-marked marine magnetic anomalies and that, in the absence of this main magnetic source made of extrusive (and perhaps intrusive material), exhumed serpentinized peridotites are not sufficiently uniform magnetic sources to produce undisputable seafloor spreading magnetic anomalies.

\subsection{Corrugated seafloor and the magnetic signal}

A corrugated surface is observed below the identified anomaly C5 toward the north end of profiles $2-2$ and 2-3 in the eastern corridor. This area is strongly magnetized (up to $10 \mathrm{~A} \mathrm{~m}^{-1}$; Figs. 2 and 3) and displays high-amplitude magnetic anomalies of up to $450 \mathrm{nT}$. This corrugated surface is surrounded by lineated volcanic terrains and the conjugate anomaly C5, on the opposite flank, was identified over wellestablished volcanic crust. This observation, together with a frequent recovery of gabbro in this area (Sauter et al., 2013), suggests that the anomaly C5 was emplaced in a more robust magmatic accretion context, before or just at the onset of continuous mantle exhumation. We thus speculate that in this particular area the magnetization is carried by extrusive or intrusive material rather than by peridotites.

\subsection{Volcanic seafloor and the magnetic signal}

Some small volcanic patches have been identified just north of the axial valley of the western corridor and within the axial region of the eastern corridor (Fig. 4). It is not clear whether this extrusive material always accounts for higher magnetization than over the smooth, exhumed mantle seafloor. The magnetic data rather confirm the interpretation of Sauter et al. (2013) based on deep-tow sonar images that these volcanics are very thin and discontinuous flows, not exceeding $100 \mathrm{~m}$ thickness, and thus do not correspond to large enough sources to be identified by the deep-tow magnetometer.

\subsection{Marine magnetic anomalies at ocean-continent transition}

Mantle exhumation is one of the proposed mechanisms responsible for the formation of the transitional domains at magma-poor rifted continental margins where serpentinized mantle-derived rocks have been drilled (Tucholke and Sibuet, 2007). Sibuet et al. (2007) proposed that a strong magnetization (up to $9 \mathrm{~A} \mathrm{~m}^{-1}$ ) can be produced by the serpentinization of a 2 to $3 \mathrm{~km}$-thick fractured layer, within the root of an active detachment fault at an embryonic spreading center. Based on NRM intensity measured in ODP holes at the Iberia margin, these authors argued that this first serpentinization phase is sufficient to preserve the polarity of the ambient magnetic field. They suggest that only the upper $10 \mathrm{~m}$ below the seafloor are affected by cold-water alteration that produces incoherent magnetic properties. Like on the SWIR, the exhumed mantle domains of the Iberia-Newfoundland margins are characterized by a weak and ill-defined magnetic signal. At these margins, only the seaward termination of the exhumed mantle domain is associated with a linear and highamplitude (up to $1000 \mathrm{nT}$ ) magnetic anomaly ("J anomaly"). This anomaly was interpreted as the end of the $M$ sequence of spreading anomalies and its amplitude was explained by a strongly serpentinized crust (Srivastava et al., 2000).

No clear seafloor spreading anomaly is observed over the exhumed mantle areas of the SWIR, neither where active detachment faulting is identified nor on the flanks. This leads to the conclusion that the serpentinization process is not sufficiently homogeneous to produce stable, large remanent magnetization. We suggest that the heterogeneous magnetization of the serpentinized peridotites strongly depends on the fluid-rock interactions, the temperature, the mineral composition and the tectonic context. Therefore, in view of the low magnetization of the young $(<11 \mathrm{Ma})$ serpentinized rock at the SWIR, it is unlikely that strong magnetic anomalies could 
be related solely to serpentinization; this would be even truer at $>100 \mathrm{Ma}$ old OCTs. Instead, it supports the hypotheses that (1) intrusive or extrusive material is required (Bronner et al., 2011; Russell and Whitmarsh, 2003) to account for a significant magnetic signal in the exhumed mantle domains of OCTs and that (2) the interpretation of this signal as resulting from seafloor spreading is precluded in the absence of a homogeneous and well-established upper oceanic crust. Consequently, the kinematic reconstructions of magma-poor passive margins using weak anomalies identified over exhumed mantle domains need to be treated with caution.

\section{Conclusions}

We have investigated the magnetic structure of newly discovered, large exhumed mantle domains of the SWIR (Sauter et al., 2013), combining high-resolution side-scan sonar images, deep-tow magnetic data and results from dredge sampling. We show that the seafloor spreading magnetic pattern disappears from the volcanic seafloor toward the exhumed mantle domains. Forward modeling allows a reasonable fit to the observed magnetic anomalies over the volcanic seafloor. However, the lack of a central magnetic anomaly and the highly heterogeneous and weak magnetic pattern observed above exhumed mantle-derived rocks prevents any identification of polarity reversals. Moreover, analysis of the magnetic properties of the dredge samples shows that serpentinized peridotites as well as gabbros are highly variable magnetic sources. We conclude that the serpentinization process is not sufficiently homogeneous to produce a significant stable magnetization on the scale of the exhumed mantle domains of the SWIR and that serpentinized peridotites are not able to contribute to regionally coherent patterns of oceanic magnetic anomalies. We further suggest that a homogeneous volcanic upper crust associated with minor tectonic activity is required to record well-defined seafloor spreading magnetic lineations.

Acknowledgements. We thank the officers and crew of the R/V Marion Dufresne for their assistance during the "Smoothseafloor" cruise. We also thank anonymous reviewers for their constructive comments that significantly improved this manuscript. Funding was provided by ANR grant "Rift2Ridge" and support by INSU/CNRS and IPEV.

Edited by: F. Speranza

\section{References}

Bronner, A., Sauter, D., Manatschal, G., Peron-Pinvidic, G., and Munschy, M.: Magmatic breakup as an explanation for magnetic anomalies at magma-poor rifted margins, Nat. Geosci., 4, 549553, doi:10.1038/ngeo1201, 2011.
Bronner, A., Sauter, D., Manatschal, G., Peron-Pinvidic, G., and Munschy, M.: Reply to "problematic plate reconstruction", Nat. Geosci, 5, 677-677, doi:10.1038/ngeo1597, 2012.

Bronner, A., Munschy, M., Sauter, D., Carlut, J., Searle, R., and Maineult, A.: Deep-tow 3c magnetic measurement: solutions for calibration and interpretation, Geophysics, 78, J15-J23, doi:10.1190/geo2012-0214.1, 2013.

Buck, W. R., Lavier, L. L., and Poliakov, A. N. B.: Modes of faulting at mid-ocean ridges, Nature, 434, 719-723, 2005.

Cann, J. R., Blackman, D. K., Smith, D. K., McAllister, E., Janssen, B., Mello, S., Avgerinos, E., Pascoe, A. R., and Escartin, J.: Corrugated slip surfaces formed at ridge-transform intersections on the mid-atlantic ridge, Nature, 385, 329-332, 1997.

Cannat, M., Bideau, D., and Bougault, H.: Serpentinized peridotites and gabbros in the mid-atlantic ridge axial valley at $15^{\circ} 37^{\prime} \mathrm{N}$ and $16^{\circ} 52^{\prime}$ N, Earth Planet. Sc. Lett., 109, 87-106, 1992.

Cannat, M., Mevel, C., Maia, M., Deplus, C., Durand, C., Gente, P., Agrinier, P., Belarouchi, A., Dubuisson, G., Humler, E., and Reynolds, J.: Thin crust, ultramafic exposures, and rugged faulting patterns at the mid-atlantic ridge $\left(22-24^{\circ} \mathrm{N}\right)$, Geology, 23, 49-52, 1995.

Cannat, M., Rommevaux-Jestin, C., Sauter, D., Deplus, C., and Mendel, V.: Formation of the axial relief at the very slow spreading southwest indian ridge $\left(49-69^{\circ}\right.$ E), J. Geophys. Res., 104, 22825-22843, 1999.

Cannat, M., Sauter, D., Mendel, V., Ruellan, E., Okino, K., Escartin, J., Combier, V., and Baala, M.: Modes of seafloor generation at a melt-poor ultraslow-spreading ridge, Geology, 34, 605-608, doi:10.1130/G22486.1, 2006.

Cannat, M., Sauter, D., Bezos, A., Meyzen, C., Humler, E., and Le Rigoleur, M.: Spreading rate, spreading obliquity, and melt supply at the ultraslow spreading southwest indian ridge, Geochem. Geophy. Geosy., 9, Q04002, doi:10.1029/2007gc001676, 2008.

Chian, D., Louden, K. E., Minshull, T. A., and Whitmarsh, R. B.: Deep structure of the ocean-continent transition in the southern Iberia Abyssal Plain from seismic refraction profiles: Ocean Drilling Program (Legs 149 and 173) transect, J. Geophys. Res.Sol. Ea., 104, 7443-7462, 1999.

Dampney, C.: The equivalent source technique, Geophysics, 34, 3953, doi:10.1190/1.1439996, 1969.

Dean, S. M., Minshull, T. A., and Whitmarsh, R. B.: Seismic constraints on the three-dimensional geometry of low-angle intracrustal reflectors in the southern iberia abyssal plain, Geophys. J. Int., 175, 571-586, 2008.

Dunlop, D. J. and Prévot, M.: Magnetic properties and opaque mineralogy of drilled submarine intrusive rocks, Geophys. J. Roy. Astr. S., 69, 763-802, doi:10.1111/j.1365-246X.1982.tb02774.x, 1982.

Flewellen, C., Millard, N., and Rouse, I.: Tobi, a vehicle for deep ocean survey, Electron. Commun. Eng., 5, 85-93, 1993.

Gee, J. S. and Kent, D. V.: Source of oceanic magnetic anomalies and the geomagnetic polarity timescale, in: Treatise on Geophysics, edited by: Schubert, G., Elsevier, 455-507, 2007.

Georgen, J. E., Lin, J., and Dick, H. J. B.: Evidence from gravity anomalies for interactions of the marion and bouvet hotspots with the southwest indian ridge: effects of transform offsets, Earth Planet. Sc. Lett., 187, 283-300, 2001. 
Harrison, C.: Marine magnetic anomalies-the origin of the stripes, Annu. Rev. Earth Pl. Sc., 15, 505-543, 1987.

Hosford, A., Tivey, M., Matsumoto, T., Dick, H., Schouten, H., and Kinoshita, H.: Crustal magnetization and accretion at the southwest indian ridge near the atlantis ii fracture zone, 0-25 ma, J. Geophys. Res.-Sol. Ea., 108, 2169, doi:10.1029/2001jb000604, 2003.

Isezaki, N.: A new shipboard three-component magnetometer, Geophysics, 51, 1992-1998, 1986.

Karson, J. A., Thompson, G., Humphris, S. E., Edmon, J. M., Bryan, W. B., Brown, J. B., Winters, A. T., Pockalny, R. A., Casey, J. F., Campbell, A. C., Klinkhammer, G. P., Palmer, M. R., Kinzler, R. J., and Sulanowska, M. M.: Along-axis variations in seafloor spreading in the mark area, Nature, 328, 681-685, 1987.

Korenaga, J.: Comprehensive analysis of marine magnetic vector anomalies, J. Geophys. Res., 100, 365-378, doi:10.1029/94jb02596, 1995.

Maffione, M., Morris, A., Plümper, O., and van Hinsbergen, D. J. J.: Magnetic properties of variably serpentinized peridotites and their implication for the evolution of oceanic core complexes, Geochem. Geophy. Geosy., n/a-n/a, doi:10.1002/2013gc004993, 2014.

Mallows, C. and Searle, R. C.: A geophysical study of oceanic core complexes and surrounding terrain, mid-atlantic ridge $13^{\circ} \mathrm{n}-14^{\circ} \mathrm{n}$, Geochem. Geophy. Geosy., 13, Q0AG08, doi:10.1029/2012gc004075, 2012.

Marshall, M. and Cox, A.: Magnetism of pillow basalts and their petrology, Geol. Soc. Am. Bull., 82, 537-552, 1971.

Mendel, V., Munschy, M., and Sauter, D.: Modmag, a matlab program to model marine magnetic anomalies, Comput. Geosci., 31, 589-597, 2005.

Meyzen, C. M., Toplis, M. J., Humler, E., Ludden, J. N., and Mevel, C.: A discontinuity in mantle composition beneath the southwest indian ridge, Nature, 421, 731-733, doi:10.1038/nature01424, 2003.

Minshull, T. A., Muller, M. R., Robinson, C. J., White, R. S., and Bickle, M. J.: Is the oceanic moho a serpentinization front?, Geological Society, London, Special Publications, 148, 71-80, doi:10.1144/gsl.sp.1998.148.01.05, 1998.

Minshull, T. A., Muller, M. R., and White, R. S.: Crustal structure of the southwest indian ridge at $66^{\circ} \mathrm{E}$ : Seismic constraints, Geophys. J. Int., 166, 135-147, 2006.

Nazarova, K. A.: Serpentinized peridotites as a possible source for oceanic magnetic anomalies, Mar. Geophys. Res., 16, 455-462, 1994.

Oufi, O., Cannat, M., and Horen, H.: Magnetic properties of variably serpentinized abyssal peridotites, J. Geophys. Res., 107, 2095, doi:10.1029/2001JB000549, 2002.

Pariso, J. E. and Johnson, H. P.: Do layer 3 rocks make a significant contribution to marine magnetic anomalies? In situ magnetization of gabbros at ocean drilling program hole $735 \mathrm{~b}$, J. Geophys. Res., 98, 16033-16052, 1993.

Patriat, P., Sauter, D., Munschy, M., and Parson, L.: A survey of the southwest indian ridge axis between atlantis ii fracture zone and the indian ocean triple junction: regional setting and large scale segmentation, Mar. Geophys. Res., 19, 457-480, doi:10.1023/a:1004312623534, 1997.
Patriat, P., Sloan, H., and Sauter, D.: From slow to ultraslow: a previously undetected event at the southwest indian ridge at ca. $24 \mathrm{Ma}$, Geology, 36, 207-210, doi:10.1130/G24270a.1, 2008.

Reston, T. J. and McDermott, K. G.: Successive detachment faults and mantle unroofing at magma-poor rifted margins, Geology, 39, 1071-1074, doi:10.1130/g32428.1, 2011.

Russell, S. M. and Whitmarsh, R. B.: Magmatism at the west iberia non-volcanic rifted continental margin: evidence from analyses of magnetic anomalies, Geophys. J. Int., 154, 706-730, doi:10.1046/j.1365-246X.2003.01999.x, 2003.

Sauter, D., Carton, H., Mendel, V., Munschy, M., RommevauxJestin, C., Schott, J.-J., and Whitechurch, H.: Ridge segmentation and the magnetic structure of the southwest indian ridge

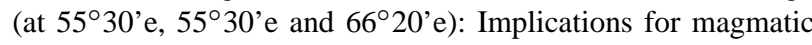
processes at ultraslow-spreading centers, Geochem. Geophy. Geosy., 5, Q05K08, doi:10.1029/2003GC000581, 2004.

Sauter, D., Cannat, M., and Mendel, V.: Magnetization of 0 $26.5 \mathrm{ma}$ seafloor at the ultraslow spreading southwest in dian ridge $61-67^{\circ} \mathrm{E}$, Geochem. Geophy. Geosy., 9, Q04023, doi:10.1029/2007GC001764, 2008.

Sauter, D., Sloan, H., Cannat, M., Goff, J., Patriat, P., Schaming, M., and Roest, W. R.: From slow to ultra-slow: How does spreading rate affect seafloor roughness and crustal thickness?, Geology, 39, 911-914, 2011.

Sauter, D., Cannat, M., Roumejon, S., Andreani, M., Birot, D., Bronner, A., Brunelli, D., Carlut, J., Delacour, A., Guyader, V., MacLeod, C. J., Manatschal, G., Mendel, V., Menez, B., Pasini, V., Ruellan, E., and Searle, R.: Continuous exhumation of mantle-derived rocks at the southwest indian ridge for 11 million years, Nat. Geosci., 6, 314-320, 2013.

Searle, R. C. and Bralee, A.: Asymmetric generation of oceanic crust at the ultra-slow spreading southwest indian ridge, $64^{\circ} \mathrm{E}$, Geochem. Geophy. Geosy., 8, Q05015, doi:10.1029/2006GC001529, 2007.

Seyler, M., Cannat, M., and Mevel, C.: Evidence for major-element heterogeneity in the mantle source of abyssal peridotites from the southwest indian ridge $\left(52^{\circ}\right.$ to $\left.68^{\circ} \mathrm{E}\right)$, Geochem. Geophy. Geosy., 4, 9101, doi:10.1029/2002gc000305, 2003.

Sibuet, J. C., Srivastava, S., and Manatschal, G.: Exhumed mantleforming transitional crust in the newfoundland-iberia rift and associated magnetic anomalies, J. Geophys. Res.-Sol. Ea., 112, B06105, doi:10.1029/2005jb003856, 2007.

Srivastava, S. P., Sibuet, J. C., Cande, S., Roest, W. R., and Reid, I. D.: Magnetic evidence for slow seafloor spreading during the formation of the newfoundland and iberian margins, Earth Planet. Sc. Lett., 182, 61-76, doi:10.1016/s0012821x(00)00231-4, 2000.

Tisseau, J. and Patriat, P.: Identification des anomalies magnétiques sur les dorsales à faible taux d'expansion: Méthode des taux fictifs, Earth Planet. Sc. Lett., 52, 381-396, doi:10.1016/0012821X(81)90191-6, 1981.

Tucholke, B. E., and Sibuet, J.-C.: Leg 210 synthesis: Tectonic, magmatic, and sedimentary evolution of the newfoundland-iberia rift, in: Proceedings of the ocean drilling program, scientific results, edited by: Tucholke, B. E., Sibuet, J.-C., and Klaus, A., Ocean Drilling Program, College Station, TX, 1-56, 2007.

Tucholke, B. E. and Sibuet, J.-C.: Leg 210 synthesis: tectonic, magmatic, and sedimentary evolution of the newfoundland-iberia rift, in: Proceedings of the ocean drilling program, scientific results, 
edited by: Tucholke, B. E., Sibuet, J.-C., and Klaus, A., Ocean Drilling Program, College Station, TX, 1-56, 2007.

Tucholke, B. E. and Sibuet, J.-C.: Problematic plate reconstruction, Nat. Geosci., 5, 676-677, doi:10.1038/ngeo1596, 2012.
Zhao, X., Turrin, B. D., Jackson, M., and Solheid, P.: Data report: Paleomagnetic and rock magnetic characterization of rocks recovered from leg 173 sites., in: Proc. Odp, sci. Results,, edited by: Beslier, M.-O., Whitmarsh, R. B., Wallace, P. J., and Girardeau, J. (Ocean Drilling Program), College Station, TX, 1-34, 2001. 